\title{
Risk factors, short and long term outcome of anastomotic leaks in rectal cancer
}

\author{
Olof Jannasch ${ }^{1,2}$, Tim Klinge ${ }^{1}$, Ronny Otto ${ }^{3}$, Costanza Chiapponi ${ }^{1}$, Andrej Udelnow ${ }^{1}$, \\ Hans Lippert ${ }^{3}$, Christiane J. Bruns ${ }^{1}$, Pawel Mroczkowski ${ }^{1,3}$ \\ ${ }^{1}$ Department for General, Visceral and Vascular Surgery, Otto-von-Guericke-University, Magdeburg, Germany \\ ${ }^{2}$ Department for General and Abdominal Surgery, AMEOS Hospital, Haldensleben, Germany \\ ${ }^{3}$ Institute for Quality Assurance in Operative Medicine, Otto-von-Guericke-University, Magdeburg, Germany \\ Correspondence to: \\ Pawel Mroczkowski, e-mail: pawel.mroczkowski@med.ovgu.de \\ Keywords: quality assurance, rectal cancer, anastomotic leak, short term outcome, long term outcome \\ Received: June 15, 2015 \\ Accepted: September 04, 2015 \\ Published: September 16, 2015
}

\section{ABSTRACT}

Background: An anastomotic leak (AL) after colorectal surgery is one major reason for postoperative morbidity and mortality. There is growing evidence that AL affects short and long term outcome. This prospective German multicentre study aims to identify risk factors for $A L$ and quantify effects on short and long term course after rectal cancer surgery.

Methods: From 1 January 2000 to 31 December 2010381 hospitals attributed patients to the prospective multicentre study Quality Assurance in Colorectal Cancer managed by the Otto-von-Guericke-University Magdeburg (Germany). Included were 17867 patients with histopathologically confirmed rectal carcinoma and primary anastomosis. Risk factor analysis included 13 items of demographic patient data, surgical course, hospital volume und tumour stage.

Results: In 2134 (11.9\%) patients an AL was diagnosed. Overall hospital mortality was $2.1 \%$ (with AL $7.5 \%$, without AL $1.4 \%$; $p<0.0001$ ). In multivariate analysis male gender, ASA-classification $\geq$ III, smoking history, alcohol history, intraoperative blood transfusion, no protective ileostomy, UICC-stage and height of tumour were independent risk factors. Overall survival (OS) was significantly shorter for patients with AL (UICC I-III; UICC I, II or III - each $p<0.0001$ ). Disease free survival (DFS) was significantly shorter for patients with AL in UICC I-III; UICC II or UICC III (each $p<0.001$ ). Rate of local relapse was not significantly affected by occurrence of AL.

Conclusion: In this study patients with AL had a significantly worse OS. This was mainly due to an increased in hospital mortality. DFS was also negatively affected by $A L$ whereas local relapse was not. This emphasizes the importance of successful treatment of AL related problems during the initial hospital stay.

\section{INTRODUCTION}

Colorectal cancer is the second most common cause of tumour-related death in Europe[1]. An anastomotic leak $(\mathrm{AL})$ is a major reason for postoperative morbidity and mortality as well as reduced quality of life [2,3]. Frequency of $\mathrm{AL}$ after rectal cancer surgery ranges from $2.6 \%$ to $19.0 \%[3-10]$. Several risk factors affecting the healing of the colorectal anastomosis have been identified $[6-8,11]$. In particular, healing of colorectal anastomosis might be affected by amount of intraoperative blood loss, tumour height (ultra-low anterior resection) and the surgeon. AL is also related to prolonged stay in hospital and increased treatment costs $[1,7,12,13]$. Furthermore, there is growing evidence that AL effects short and long term survival and frequency of tumour relapse $[14,15]$. Based on the data 
of the multicentre International Quality Assessment Study in Colorectal Cancer [16] we looked for risk factors and consequences of AL in surgery of rectal cancer.

\section{RESULTS}

From 1 January 2000 to 31 December 2010 a total of 17867 patients from 381 hospitals fulfilled the inclusion criteria. Detailed patient characteristics are given in Table 1. AL occurred in 2134 (11.9\%) cases. Hospital mortality was $2.1 \%$ and demonstrated significant difference between patients with $(7.5 \%)$ and without (1.4\%) AL $(p<0.0001)$.

Univariate analysis revealed gender, ASAclassification, smoking, alcohol, intraoperative blood transfusion, no protective ileostomy, UICC-stage and height of tumour as significant risk factors. Results are given in Table 2. Gender, ASA-classification, smoking, alcohol, intraoperative blood transfusion, no protective ileostomy, UICC-stage and height of tumour remained significant in multivariate analysis. Results are given in Table 3.

Median follow-up was 30 months and included $79.9 \%$ of patients, who gave consent for data collection ( $81 \%$ of the entire cohort). Patients with AL had a lower probability of the OS. The difference was significant for the whole cohort $(p<0.0001)$ as well as for the subgroups (UICC I, II, III - each $p<0.0001$ ). Further analysis revealed that this difference originates from in hospital death. Whereas probability of overall survival differed significantly for the entire cohort, no significant difference could be shown for both groups, if patients who died during the hospital stay were excluded. Detailed data are shown in Figure 1 as well as in Table 4.

DFS was also effected by AL. The difference was significant for the whole cohort $(p<0.0001)$ as well as for the subgroups (UICC I $-p=0.005$; UICC II $-p=0.001$; UICC III $-p<0.0001)$. Patients with AL and UICC I displayed an increased 5-year DFS. Otherwise, patients with UICC II, UICC III or the whole cohort had an decreased DFS. As for OS no group difference could be shown, if patients who died during the hospital stay were excluded. Detailed data are shown in Figure 2 as well as in Table 5.

AL had no significant effect on the probability of local relapse (UICC I-III $p=0.240$, UICC I $p=0.671$, UICC II $p=0.376$, UICC III $p=0.704$ ) as demonstrated in Table 6 .

\section{DISCUSSION}

The observed AL rate of $11.9 \%$ fits in the range from 2.7 to $19 \%$ described in other studies [5, 10, 13, 20-26]. Multivariate analysis displayed male gender, smoking, alcohol use, UICC-stage III, ASA-classification III+IV, intraoperative blood transfusion, no protective ileostomy, tumour localisation in the middle and lower rectum as independent risk factors for AL.

\section{Patient-related factors}

Male gender was accompanied by a 1.7 fold risk for AL. This was confirmed by other studies (OR 1.49 - 2.36) $[5,10,13,24]$ and might be attributed to the anatomical difference in comparison to the wider female pelvis. Furthermore use of alcohol and smoking is more common in male. The well-known negative effect on general wound healing $[5,26]$ might explain that smoking history was an independent risk factor for AL in this study (OR 1.3). Others estimated the negative effect even higher [27]. Richards et al. found on multivariate analysis that current smokers have a significantly increased risk for AL undergoing low anterior resection (OR 3.68, 95\% CI

Table 1: Detailed patient characteristics

\begin{tabular}{|c|c|c|c|c|}
\hline & Total & patients with $\mathrm{AL}$ & patients without $\mathrm{AL}$ & $p$ \\
\hline patients $n(\%)$ & $17867(100 \%)$ & $2134(11.9 \%)$ & $15733(88.1 \%)$ & $<0.0001 *$ \\
\hline gender $n(\%)$ & $17827(100 \%)$ & $2127(11.9 \%)$ & $15700(88.1 \%)$ & $<0.0001 *$ \\
\hline (ratio - male:female) & $1.4: 1$ & $2.5: 1$ & $1.3: 1$ & \\
\hline mean age (years \pm SD) & $66.95 \pm 10.54$ & $66.31 \pm 10.24$ & $67.03 \pm 10.57$ & $<0.0001 * *$ \\
\hline $\begin{array}{l}\text { mean body mass index } \\
\left(\mathrm{kg} / \mathrm{m}^{2} \pm \mathrm{SD}\right)\end{array}$ & $26.49 \pm 4.22$ & $26.54 \pm 4.24$ & $26.49 \pm 4.21$ & $0.485 * *$ \\
\hline $\begin{array}{l}\text { mean stay in hospital } \\
\text { (days } \pm \text { SD) }\end{array}$ & $21 \pm 12.7$ & $37 \pm 19.9$ & $19 \pm 9.8$ & $<0.0001 * *$ \\
\hline hospital mortality $n(\%)$ & $379(2.1 \%)$ & $160(7.5 \%)$ & $219(1.4 \%)$ & $<0.0001 *$ \\
\hline
\end{tabular}

${ }^{*}$ Chi-square test

** Mann-Whitney- $U$-test

$\mathrm{AL}$ - anastomotic leakage 
entire cohort

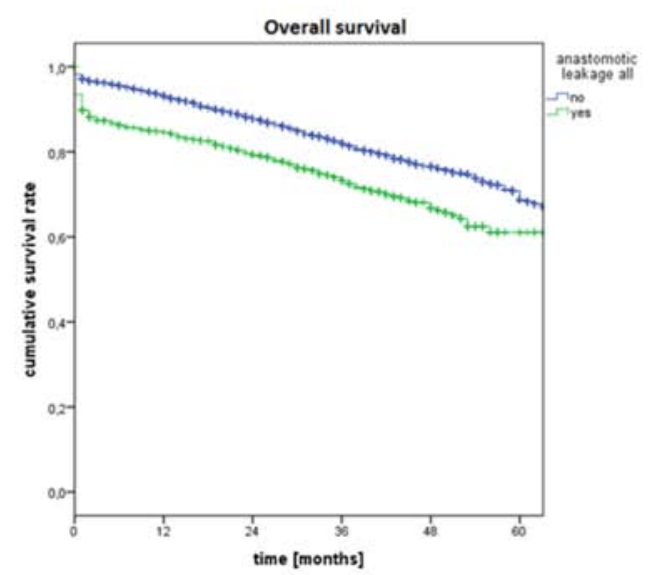

No. at risk: entire cohort $(\% / n)$

\begin{tabular}{|c|c|c|c|c|c|c|}
\hline months & 0 & 12 & 24 & 36 & 48 & 60 \\
\hline no AL & $98.2 \%$ & $93.1 \%$ & $87.8 \%$ & $81.9 \%$ & $76.6 \%$ & $68.8 \%$ \\
& 8897 & 5571 & 4765 & 3170 & 1112 & 166 \\
\hline AL & $93.4 \%$ & $84.6 \%$ & $79.3 \%$ & $73.3 \%$ & $66.7 \%$ & $61.1 \%$ \\
& 1169 & 701 & 612 & 409 & 150 & 44 \\
\hline
\end{tabular}

Figure 1: Probability of 5-year overall survival.

entire cohort

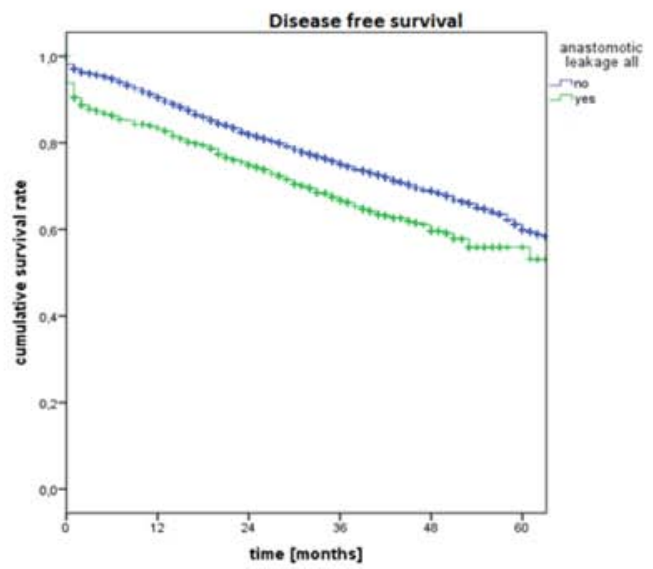

No. at risk: entire cohort $(\% / n)$

\begin{tabular}{|c|c|c|c|c|c|c|}
\hline months & 0 & 12 & 24 & 36 & 48 & 60 \\
\hline no AL & $98.2 \%$ & $90.4 \%$ & $81.9 \%$ & $75.1 \%$ & $68.8 \%$ & $59.9 \%$ \\
& 8702 & 5299 & 4387 & 2895 & 1011 & 143 \\
\hline AL & $93.8 \%$ & $83.3 \%$ & $74.9 \%$ & $66.7 \%$ & $59.7 \%$ & $55.9 \%$ \\
& 1144 & 672 & 565 & 365 & 128 & 59 \\
\hline
\end{tabular}

hospital mortality excluded

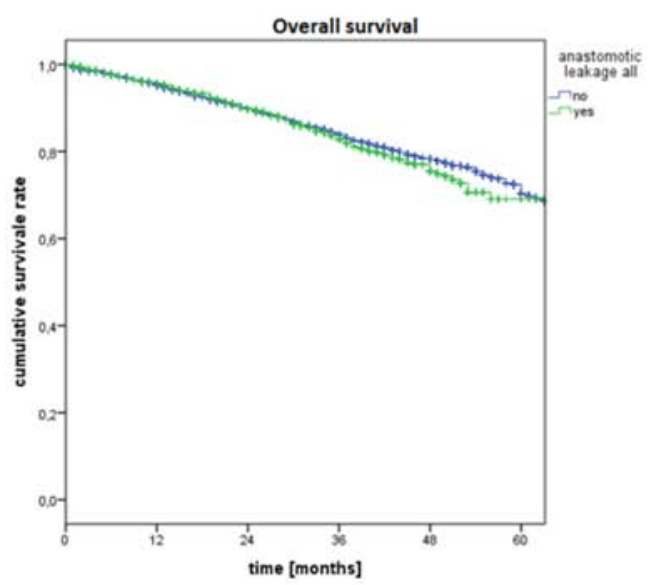

No. at risk: hospital mortality excluded (\%/n)

\begin{tabular}{|c|c|c|c|c|c|c|}
\hline months & 0 & 12 & 24 & 36 & 48 & 60 \\
\hline no AL & $99.9 \%$ & $95.2 \%$ & $89.7 \%$ & $83.8 \%$ & $78.3 \%$ & $70.3 \%$ \\
& 8868 & 5571 & 4765 & 3170 & 1112 & 166 \\
\hline AL & $100 \%$ & $95.7 \%$ & $89.7 \%$ & $82.9 \%$ & $75.5 \%$ & $69.1 \%$ \\
& 1118 & 701 & 612 & 409 & 150 & 44 \\
\hline
\end{tabular}

\section{hospital mortality excluded}

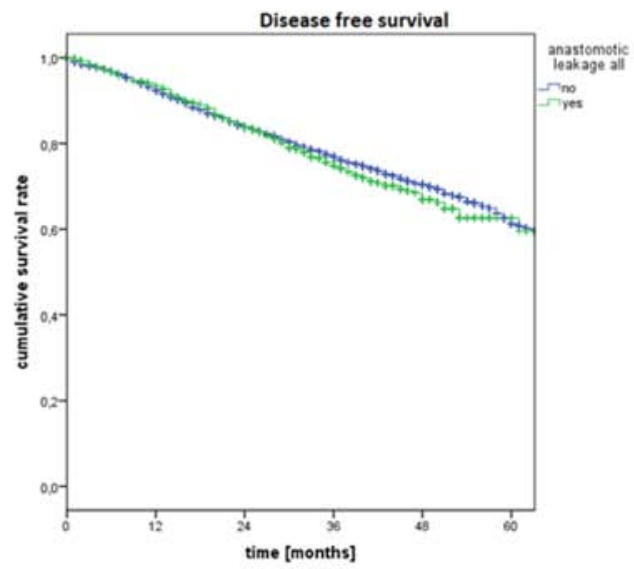

No. at risk: hospital mortality excluded (\%/n)

\begin{tabular}{|c|c|c|c|c|c|c|}
\hline months & 0 & 12 & 24 & 36 & 48 & 60 \\
\hline no AL & $99.8 \%$ & $92.4 \%$ & $83.7 \%$ & $76.8 \%$ & $70.3 \%$ & $61.2 \%$ \\
& 8673 & 5299 & 4387 & 2895 & 1011 & 143 \\
\hline AL & $99.8 \%$ & $93.4 \%$ & $83.9 \%$ & $74.8 \%$ & $66.9 \%$ & $62.7 \%$ \\
& 908 & 672 & 565 & 365 & 128 & 59 \\
\hline
\end{tabular}

Figure 2: Probability of 5-year disease free survival. 
Table 2: Risk factors for anastomotic leakage - univariate analysis

\begin{tabular}{|c|c|c|c|c|}
\hline & $n$ & anastomotic leakage $n(\%)$ & no anastomotic leakage $n(\%)$ & $p$ \\
\hline male & 10477 & $1524(14.5 \%)$ & $8953(85.5 \%)$ & $<0.0001$ \\
\hline female & 7350 & $603(8.2 \%)$ & $6747(91.8 \%)$ & \\
\hline age $\leq 68$ years & 9592 & $1170(12.2 \%)$ & $8422(87.8 \%)$ & 0.261 \\
\hline age $>68$ years & 8266 & $963(11.7 \%)$ & $7303(88.3 \%)$ & \\
\hline $\mathrm{BMI} \leq 25 \mathrm{~kg} / \mathrm{m}^{2}$ & 8513 & $1010(11.9 \%)$ & $7503(88.1 \%)$ & 0.945 \\
\hline $\mathrm{BMI}>25 \mathrm{~kg} / \mathrm{m}^{2}$ & 8707 & $1036(11.9 \%)$ & $7671(88.1 \%)$ & \\
\hline ASA I and II & 11733 & $1314(11.2 \%)$ & $10419(88.8 \%)$ & $<0.0001$ \\
\hline ASA III and IV & 6107 & $818(13.4 \%)$ & $5289(86.6 \%)$ & \\
\hline smoking yes & 954 & $165(17.3 \%)$ & $789(82.7 \%)$ & $<0.0001$ \\
\hline smoking no & 16804 & $1953(11.6 \%)$ & $14851(88.4 \%)$ & \\
\hline alcohol yes & 347 & $74(21.3 \%)$ & $273(78.7 \%)$ & $<0.0001$ \\
\hline alcohol no & 17411 & $2044(11.7 \%)$ & $15367(88.3 \%)$ & \\
\hline diabetes mellitus yes & 1114 & $140(12.6 \%)$ & $974(87.4 \%)$ & 0.496 \\
\hline diabetes mellitus no & 16644 & $1978(11.9 \%)$ & $14666(88.1 \%)$ & \\
\hline hospital volume $<14$ ppy & 4632 & $541(11.7 \%)$ & $4091(88.3 \%)$ & 0.314 \\
\hline hospital volume 15-24 ppy & 4737 & $543(11.5 \%)$ & $4194(88.5 \%)$ & \\
\hline hospital volume 25-36 ppy & 4213 & $544(12.1 \%)$ & $3669(87.9 \%)$ & \\
\hline hospital volume $>36$ ppy & 3985 & $506(12.7 \%)$ & $3479(87.3 \%)$ & \\
\hline stapled anastomosis & 16612 & $1983(11.9 \%)$ & $14629(88.1 \%)$ & 0.721 \\
\hline hand sutured anastomosis & 1046 & $121(11.6 \%)$ & $925(88.4 \%)$ & \\
\hline blood transfusion yes & 228 & $39(17.1 \%)$ & $189(82.9 \%)$ & 0.016 \\
\hline blood transfusion no & 17639 & $2095(11.9 \%)$ & $15544(88.1 \%)$ & \\
\hline ileostomy yes & 7148 & $893(12.5 \%)$ & $6255(87.5 \%)$ & 0.003 \\
\hline ileostomy no & 5057 & $724(14.3 \%)$ & $4333(85.7 \%)$ & \\
\hline UICC I & 6457 & $721(11.2 \%)$ & $5736(88.8 \%)$ & 0.004 \\
\hline UICC II & 5162 & $600(11.6 \%)$ & $4562(88.4 \%)$ & \\
\hline UICC III & 6248 & $813(13.0 \%)$ & $5435(87.0 \%)$ & \\
\hline tumour heigth $<6 \mathrm{~cm}$ & 1703 & $256(15.0 \%)$ & $1447(85.0 \%)$ & $<0.0001$ \\
\hline tumour heigth $6-12 \mathrm{~cm}$ & 11144 & $1421(12.8 \%)$ & $9723(87.2 \%)$ & \\
\hline tumour heigth $>12 \mathrm{~cm}$ & 4501 & $400(8.9 \%)$ & $4101(91.1 \%)$ & \\
\hline
\end{tabular}

p for Chi-square test, ASA - classification of the American Society of Anaesthesiologists, ppy - patients per year

$1.38-9.82, p=0.009)[6]$. Even though alcohol history was associated with a higher risk for AL than smoking (OR 1.6 vs. 1.3) a generally negative effect on wound healing is not proven. A limiting factor for analysing the effect of alcohol and smoking is the reliability of the patients report.

ASA- classification III or IV has been identified as risk factor for wound healing disturbances [10, 28].
However, Bertelsen et al. did not find a significant correlation between ASA-classification and AL, but in this study only ASA-score I and II were included [5]. Chemoor radiochemotherapy (neo-adjuvant or adjuvant) might alter risk of anastomotic leak [10, 29]. This risk factor was not included in the current analysis. Particularly neoadjuvant treatment was no standard treatment in the entire cohort. 
Table 3: Risk factors for anastomotic leakage - multivariate analysis

\begin{tabular}{|l|c|c|c|c|}
\hline \multicolumn{2}{|c|}{$p$} & 1 & \\
\hline tumour height $>\mathbf{1 2} \mathbf{~ c m ~}$ & & 2.120 & 1.765 \\
\hline tumour height $\mathbf{6}-\mathbf{1 2} \mathbf{~ c m}$ & $<\mathbf{0 . 0 0 0 1}$ & 1.619 & 1.428 & 2.546 \\
\hline tumour height $<\mathbf{6} \mathbf{~ c m}$ & $<\mathbf{0 . 0 0 0 1}$ & 1.923 & 1.733 & 1.835 \\
\hline male & $<\mathbf{0 . 0 0 0 1}$ & 1.510 & 1.055 & 2.133 \\
\hline intraop. blood transfusion & $\mathbf{0 . 0 2 4}$ & 1 & 0.906 \\
\hline UICC I & & 1.022 & 1.100 \\
\hline UICC II & 0.724 & 1.228 & 1.106 \\
\hline UICC III & $<\mathbf{0 . 0 0 0 1}$ & $\mathbf{0 . 0 0 2}$ & 1.332 & 1.372 \\
\hline smoking & $<\mathbf{0 . 0 0 0 1}$ & $\mathbf{0 . 0 0 1}$ & 1.222 & 1.604 \\
\hline no ileostomy & $<\mathbf{0 . 0 0 0 1}$ & 1.214 & 1.233 \\
\hline alcohol & & & 1.101 \\
\hline ASA-classification III + IV & & & 1.351 \\
\hline
\end{tabular}

CI - confidence interval

Table 4: Probability of 5-year overall survival according to tumour stage and occurrence of anastomotic leak

\begin{tabular}{|c|c|c|c|c|c|c|c|c|}
\hline \multirow[t]{2}{*}{ tumour stage } & \multicolumn{4}{|c|}{$5 y-O S$} & \multicolumn{4}{|c|}{ 5y-OS - without hospital mortality } \\
\hline & total & AL yes & AL no & $p$ & total & AL yes & AL no & $p$ \\
\hline UICC I-III & $67.8 \%$ & $61.1 \%$ & $68.8 \%$ & $<0.0001$ & $70.2 \%$ & $69.1 \%$ & $70.3 \%$ & 0.339 \\
\hline UICC I & $80.0 \%$ & $78.8 \%$ & $80.1 \%$ & $<0.0001$ & $82.2 \%$ & $85.8 \%$ & $81.7 \%$ & 0.913 \\
\hline UICC II & $66.5 \%$ & $59.9 \%$ & $67.3 \%$ & $<0.0001$ & $69.0 \%$ & $68.5 \%$ & $68.9 \%$ & 0.837 \\
\hline UICC III & $56.6 \%$ & $46.9 \%$ & $58.2 \%$ & $<0.0001$ & $58.9 \%$ & $54.3 \%$ & $59.5 \%$ & 0.764 \\
\hline
\end{tabular}

$p$ for Chi-square test, AL - anastomotic leakage, OS - overall survival

\section{Tumour-related factors}

In comparison to UICC stage I - stage II does not increase risk for AL. This is consistent with findings of other authors[30]. Smith analyzed the effect of UICC stage in general on rate of AL and did not find a statistical significant correlation $(p=0.15)[21]$. However, in a bootstrap analysis Warschkow et al. identified UICC stage III or IV as risk factor for AL[22]. Bertelsen et al. reported no statistical influence of tumour stage on risk of AL[5]. The classification of the tumour stage highly depends on the assessment of the specimen by the local pathologist and might be a subject of interobserver variation[31].

Several studies reported a correlation between tumour height and rate of AL. Highest risk was found for anastomosis in the lower rectum[5, 22, 23]. In the current study we found the highest risk for anastomoses in the middle rectum (OR 2.2 for middle rectum vs. OR
1.8 for lower rectum). A speculative explanation could be selection of more experienced surgeons for performing a lower resection and anastomosis, but our data do not deliver this information. Otherwise, a currently published systematic review by McDermott et al. states that for rectal procedures the distance from the anal margin is a significant predictor of AL, with the risk increasing the closer the tumour is to the anal margin[10].

\section{Surgery-related factors}

Hospital-volume did not show significant impact even in the univariate analysis. The discussion about the role of the hospital-volume lasts for nearly 20 years and is mostly supported by American data[32] with limited reproduction in Europe. It is possible that a volume-effect is not present or far reduced in hospitals participating in quality-assurance programs, as reported by our group 
Table 5: Probability of disease free survival according to tumour stage and occurrence of an anastomotic leak

\begin{tabular}{|c|c|c|c|c|c|c|c|c|}
\hline \multirow[t]{2}{*}{ tumour stage } & \multicolumn{4}{|c|}{ 5-y DFS } & \multicolumn{4}{|c|}{ 5y-DFS - without hospital mortality } \\
\hline & total & AL yes & AL no & $p$ & total & AL yes & AL no & $p$ \\
\hline UICC I-III & $59.4 \%$ & $55.9 \%$ & $59.9 \%$ & $<0.0001$ & $61.4 \%$ & $62.7 \%$ & $61.2 \%$ & 0.389 \\
\hline UICC I & $73.9 \%$ & $75.1 \%$ & $73.6 \%$ & 0.005 & $95.9 \%$ & $81.8 \%$ & $75.1 \%$ & 0.769 \\
\hline UICC II & $57.1 \%$ & $55.9 \%$ & $75.0 \%$ & 0.001 & $59.2 \%$ & $63.7 \%$ & $58.4 \%$ & 0.553 \\
\hline UICC III & $46.3 \%$ & $38.9 \%$ & $47.5 \%$ & $<0.0001$ & $48.0 \%$ & $44.2 \%$ & $48.5 \%$ & 0.268 \\
\hline
\end{tabular}

$p$ for Chi-square test, AL - anastomotic leakage, DFS - disease free survival

Table 6: Probability of a local relapse according to tumour stage and occurrence of an anastomotic leakage

\begin{tabular}{l|c|c|c|c|}
\hline Local relapse & \multicolumn{1}{c}{ total } & AL yes & AL no & $p$ \\
\hline UICC I-III & $9.3 \%$ & $8.3 \%$ & $9.4 \%$ & 0.240 \\
\hline UICC I & $5.4 \%$ & $4.6 \%$ & $5.5 \%$ & 0.671 \\
\hline UICC II & $8.2 \%$ & $8.0 \%$ & $8.4 \%$ & 0.376 \\
\hline UICC III & $15.2 \%$ & $12.1 \%$ & $15.7 \%$ & 0.704 \\
\hline
\end{tabular}

$p$ for Chi-square test, $\mathrm{AL}$ - anastomotic leakage

for colon cancer [17] and recently also from the Belgian PROCARE programme [33].

Intraoperative blood transfusion has been identified as risk factor for $\mathrm{AL}[5,10,22]$. It is also known as a risk factor for wound healing disturbances in general [34]. However, there seems to be an effect of the amount of blood given during operation $[22,35]$. In the current study we found a 1.5 -fold risk for AL without differentiation of the amount of blood units given. The possible biologic mechanisms of the worse outcomes were widely discussed before [36], but in any case blood loss is a proxy for surgical quality and subtle preparation technique. Protective ileostomy has been identified as effective procedure to reduce risk of AL [5, 21-23, 37-39], also in a recently published Indian randomized controlled trial [40]. This is supported by the finding of the current study. Lack of an ileostomy increased the risk for an $\mathrm{AL}$ (OR 1.2), so we also support faecal diversion for reduction of AL. Since we have no data about the percentage of low anastomosis vs. anastomosis in the mid-rectum the relation of ileostomy and anastomotic leak is correlated with tumour height. However, creation of a stoma might only lessen the consequences but not the prevalence of AL [10].

\section{Longterm results}

The current study could demonstrate a significant negative effect of AL on OS in rectal cancer surgery. This can mainly be attributed to the in hospital mortality in the postoperative course, probably resulting from septic problems. Tumour biology does not seem to be affected, as the OS of AL survivors does not differ. Bertelsen et al. demonstrated a 4-fold 30-days-mortality in case of AL in a multicentre study including 1494 patients with rectal cancer [4]. A meta-analysis by Mirnezami et al. demonstrated a significantly higher specific long term cancer mortality after AL (OR $1.75 ; 95 \% \mathrm{CI}=1.47-2.1$; $p=0.0001$ ) [41]. But this analysis is based on studies published between 1965-2009. Even though it comprises data of 21902 patients from 21 studies only 1 prospective randomized study is included. Otherwise, Mrak et al. did not find a correlation between $\mathrm{AL}$ and $\mathrm{OS}$ in a unicentre study with 811 patients [42]. Even though number of included patients is small in that study, follow up was 20 years. A follow up of the Swedish rectal cancer registry from 1995-1997 did also not show a correlation between $\mathrm{AL}$ and $\mathrm{OS}$ but also demonstrated a higher 30-days -mortality of patients with AL [25]. In conclusion, it seems as if the patient survives an AL he may not experience disadvantages concerning his OS. It also implies that patients having multiple risk factors for AL should be treated in specialized centres.

We could demonstrate a statistical significant effect of AL on DFS $(p<0.0001)$ but not for local relapse $(p=0.958)$. Otherwise, DFS did not differ between groups if in hospital mortality was excluded. So again tumour biology does not seem to be affected, in survivors of AL. This correlates with other findings. Mrak et al. and 
Smith et al. did also not find a correlation between AL and either DFS or local relapse $[21,42]$. Multivariate analyses of the Danish national Register did not show an increase of local and distant recurrence in patients with AL after anterior resection for rectal cancer [4]. Ptok et al. could demonstrate a higher 5-year local relapse rate (4.3 vs. $1.2 \%, p=0.006$ ) for patients with AL necessitating surgical treatment [43]. But currently interventional drainage of abscesses is largely available und reduces rate of reoperation. Mirzenami et al. could also demonstrate an increased risk for developing a local relapse after rectal anastomoses (OR 2.05; 95\% CI $=1.51-2.8 ; p=0.0001$ ) [41]. But significant heterogeneity was detected in the local recurrence outcomes, which may indicate that the data was not suitable for pooling.

According to Jörgren et al. DFS seems to be affected during the first few years but not so in the long term course [25]. Differences between findings may also result from different definitions of AL. Jörgren et al. defined AL by "symptoms or clinical signs" [25] whereas Bertelsen et al. provide a detailed definition: "AL was defined as follows: peritonitis and a defect in the anastomosis, discharge of pus from the anus, and recto-vaginal fistula or faeces or gas from the abdominal drain. Leakage was confirmed by endoscopy, CT scan, contrast enema, reoperation or digital rectal examination" [4]. Efforts to unify classification of anastomotic leakage are under progress, but an implementation is a future question [20].

A limitation of our study is the quality of the followup data. Even though there is an improvement in cancer documentation in Germany[44], the reporting is based mostly on family physician's goodwill. This voluntary programme without public support could not compare the documented data with clinical reality.

\section{MATERIALS AND METHODS}

\section{Study design and data assessment}

The analysis concerned patients with cancer of the rectum treated from 1 January 2000 to 31 December 2010 and recorded in the prospective International Quality Assessment Study in Colorectal Cancer managed by the Otto-von Guericke-University Magdeburg (Germany). The project was voluntary and based on the anonymity of both patients and hospitals. 381 of 1100 German hospitals performing anterior resection of the rectum could be included in this study. Data were provided by surgical departments for every patient treated for colorectal cancer and documented in a structured questionnaire by the attending surgeon. Included were all patients with histopathologically confirmed rectal carcinoma and primary anastomosis. The hospitals were required to deliver data on every patient treated for rectal cancer and the total number of reported patients was cross-checked with the hospital's financial report for the insurance companies to avoid a selection bias [17].

Preoperative bowel preparation, placement of drains, creation of ileostomy or postoperative participation in an enhanced recovery programme were scheduled by the responsible department or surgeon. Anastomotic leak was diagnosed at the discretion of the providing surgeon whether by clinical and/or radiological means.

Exclusion criteria were (a) cancer localized higher than $16 \mathrm{~cm}$ from the anal verge, (b) anal carcinoma, (c) treatment outside of Germany, (d) tumour stage UICC IV.

Demographic data included age, gender, body mass index (BMI - $<25 \mathrm{~kg} / \mathrm{m}^{2}$ vs. $>25 \mathrm{~kg} / \mathrm{m}^{2}$ ), American Society of Anaesthesiologists - Classification[18] (ASA) I+II vs. III+IV, smoking and alcohol history, diabetes.

Surgical course included type of anastomosis (stapled vs. hand suture), intraoperative blood transfusion, use of protective ileostomy, length of hospital stay, hospital mortality. For estimation of volume effect hospitals were classified into four groups based on quadrilles of patients treated annually (<14 patients per year (ppy), 15-24 ppy, 25-36 ppy, >36 ppy). Tumour stage was classified according to the UICC-classification. UICC stage was based on classification by the local pathologist. Patients with UICC stage IV were excluded. Tumour height was given as distance from the anal verge to the lower tumour border measured in rigid rectoscopy. The localization was then classified as lower rectum $(0-6 \mathrm{~cm})$, middle rectum $(6-12 \mathrm{~cm})$ and upper rectum $(12-16 \mathrm{~cm})$. Adjuvant treatment complied with the German S3-guidelines [19], but was left at the discretion of the responsible surgeon, oncologist or general practitioner. Follow up was based on the information received from family physicians, responsible for postoperative care in the German health system. Data were collected using a structured form provided by the Institute for Quality Assurance in Operative Medicine, Ottovon-Guericke-University, Magdeburg, Germany. Follow up was conducted annually. When available, data from local tumour registers were cross-checked.

\section{Statistical analysis}

All constant variables were used with appropriate measurements and given as mean with standard deviation, minimum and maximum or as median with $25^{\text {th }}$ to $75^{\text {th }}$ percentile, minimum and maximum. Categorical variables were displayed as absolute or relative frequencies. Chisquare test was used to proof independency of categorical variables. For small sample numbers $(<5)$ Crosstabulation or Fisher's exact test were used. For estimation of systematic differences between groups test of normal distribution was performed (Shapiro-Wilk-test). In case of normal distribution of variables $T$-test was used and for non-even distribution of data $U$-test. Furthermore data 
were calculated for probability of survival according to Kaplan-Meier-model. Groups were compared using logrank-testing in relation to survival. Additionally median survival with $95 \%$ confidence interval was calculated.

Risk factor analysis for occurrence of anastomotic leakage was first performed univariate. All statistical significant variables were further calculated using a multivariate regression and displayed as odds ratio with 95\%-confidence interval. Significance was considered if $p<0.05$. Statistical analysis was performed with IBM $^{\circledR}$ SPSS $^{\circledR}$ Statistics, Version 21.0.0, SPSS Inc. (New York, USA).

This study was approved by the local ethics committee and was undertaken with the understanding and appropriate informed consent of each patient included. Written consent was obtained from each patient.

\section{CONCLUSION}

With $11.9 \%$ AL remains a common and serious complication of curative surgery in rectal cancer. In multivariate analysis male gender, ASA-classification $\geq$ III, smoking history, alcohol history, intraoperative blood transfusion, no protective ileostomy, UICC-stage and height of tumour were independent risk factors. The majority of these factors is patient- and tumour-dependent and cannot be influenced by the surgeon. Only creation of a protective stoma as well as intraoperative blood transfusion remain at the surgeon's discretion. Anastomotic leakage does limit overall survival and disease free survival, but this difference is generated during the initial hospital stay. Despite the efforts of minimising the risk of AL, early detection and successful treatment of this complication (intensive care, interventional radiology etc.) seem to be crucial for preventing the negative influence on survival. This could support selection of high-risk patients (male, advanced tumours, ASA III-IV, smoking and/or alcohol history) for treatment in hospitals providing these services.

\section{CONFLICTS OF INTEREST}

For the publication of the submitted article O. Jannasch, T. Klinge, R. Otto, C. Chiapponi, A. Udelnow, H. Lippert, C.J. Bruns and P. Mroczkowski have no conflict of interest to declare.

\section{Editorial note}

This paper has been accepted based in part on peerreview conducted by another journal and the authors' response and revisions as well as expedited peer-review in Oncotarget.

\section{Synopsis}

Anastomotic leaks are a major complication in rectal cancer surgery and occur in approximatly $11.9 \%$. This increases hospital mortality and worsens overall survival. However, for patients leaving hospital alive overall survival, disease free survival and local relapse are not affected.

\section{Presentation}

Parts of the results have been presented at the 132 . Congress of the German Society of Surgery in Munich, April 2015

\section{REFERENCES}

1. Sant M, Allemani C, Santaquilani M, Knijn A, Marchesi F, Capocaccia R. EUROCARE-4. Survival of cancer patients diagnosed in 1995-1999. Results and commentary. Eur J Cancer. 2009; 45:931-991.

2. Gong JP, Yang L, Huang XE, Sun BC, Zhou JN, Yu DS, et al. Outcomes based on risk assessment of anastomotic leakage after rectal cancer surgery. Asian Pac J Cancer Prev. 2014; 15:707-712.

3. Brown SR, Mathew R, Keding A, Marshall HC, Brown JM, Jayne DG. The impact of postoperative complications on long-term quality of life after curative colorectal cancer surgery. Ann Surg. 2014; 259:916-923.

4. Bertelsen CA, Andreasen AH, Jorgensen T, Harling H. Anastomotic leakage after curative anterior resection for rectal cancer: short and long term outcome. Colorectal Dis. 2010; 12:e76-81 10.1111/j.1463-1318.2009.01935.x.

5. Bertelsen CA, Andreasen AH, Jorgensen T, Harling H. Anastomotic leakage after anterior resection for rectal cancer: risk factors. Colorectal Dis. 2010; 12:37-43.

6. Richards $\mathrm{CH}$, Campbell V, Ho C, Hayes J, Elliott T, Thompson-Fawcett M. Smoking is a major risk factor for anastomotic leak in patients undergoing low anterior resection. Colorectal Dis. 2012; 14:628-633.

7. Sajid MS, Ahamd A, Miles WF, Baig MK. Systematic review of oncological outcomes following laparoscopic vs open total mesorectal excision. World J Gastrointest Endosc. 2014; 6:209-219.

8. Damen N, Spilsbury K, Levitt M, Makin G, Salama P, Tan P, et al. Anastomotic leaks in colorectal surgery. ANZ J Surg. 2014; 84:763-768 10.1111/ans.12494.

9. Eriksen MT, Wibe A, Norstein J, Haffner J, Wiig JN. Anastomotic leakage following routine mesorectal excision for rectal cancer in a national cohort of patients. Colorectal Dis. 2005; 7:51-57.

10. McDermott FD, Heeney A, Kelly ME, Steele RJ, Carlson GL, Winter DC. Systematic review of preoperative, intraoperative and postoperative risk factors for colorectal anastomotic leaks. Br J Surg. 2015; 102:462-79.

11. Vermeer TA, Orsini RG, Daams F, Nieuwenhuijzen GA, Rutten HJ. Anastomotic leakage and presacral abscess formation after locally advanced rectal cancer 
surgery: Incidence, risk factors and treatment. Eur J Surg Oncol. 2014; 40:1502-1509 10.1016/j.ejso.2014.03.019.

12. Ashraf SQ, Burns EM, Jani A, Altman S, Young JD, Cunningham $\mathrm{C}$, et al. The economic impact of anastomotic leakage after anterior resections in English NHS hospitals: are we adequately remunerating them?. Colorectal Dis. 2013; 15:e190-198.

13. Kang CY, Halabi WJ, Chaudhry OO, Nguyen V, Pigazzi A, Carmichael JC, et al. Risk factors for anastomotic leakage after anterior resection for rectal cancer. JAMA Surg. 2013; 148:65-71.

14. den DM, Marijnen CA, Collette L, Putter H, Pahlman L, Folkesson J, et al. Multicentre analysis of oncological and survival outcomes following anastomotic leakage after rectal cancer surgery. Br J Surg. 2009; 96:1066-1075.

15. Penninckx F. Anastomotic leakage: a disaster or a challenge with an impact on survival after rectal cancer surgery? Colorectal Dis. 2011; 13:237-238.

16. Mroczkowski P, Kube R, Schmidt U, Gastinger I, Lippert H. Quality assessment of colorectal cancer care: an international online model. Colorectal Dis. 2011; 13:890-895.

17. Mroczkowski P, Kube R, Ptok H, Schmidt U, Hac S, Kockerling F, et al. Low-volume centre vs high-volume: the role of a quality assurance programme in colon cancer surgery. Colorectal Dis. 2011; 13:e276-283.

18. Saklad M. Grading of Patients for Surgical Procedures. Anesthesiology. 1941; 2:281-284.

19. Pox CP, Schmiegel W. [German S3-guideline colorectal carcinoma]. Dtsch Med Wochenschr. 2013; 138:2545 10.1055/s-0033-1353953.

20. Kulu Y, Ulrich A, Bruckner T, Contin P, Welsch T, Rahbari NN, et al. Validation of the International Study Group of Rectal Cancer definition and severity grading of anastomotic leakage. Surgery. 2013; 153:753-761.

21. Smith JD, Paty PB, Guillem JG, Temple LK, Weiser MR, Nash GM. Anastomotic leak is not associated with oncologic outcome in patients undergoing low anterior resection for rectal cancer. Ann Surg. 2012; 256:1034-1038.

22. Warschkow R, Steffen T, Thierbach J, Bruckner T, Lange J, Tarantino I. Risk factors for anastomotic leakage after rectal cancer resection and reconstruction with colorectostomy. A retrospective study with bootstrap analysis. Ann Surg Oncol. 2011; 18:2772-2782.

23. Eberl T, Jagoditsch M, Klingler A, Tschmelitsch J. Risk factors for anastomotic leakage after resection for rectal cancer. Am J Surg. 2008; 196:592-598.

24. Caulfield H, Hyman NH. Anastomotic leak after low anterior resection: a spectrum of clinical entities. JAMA Surg. 2013; 148:177-182.

25. Jorgren F, Johansson R, Damber L, Lindmark G. Anastomotic leakage after surgery for rectal cancer: a risk factor for local recurrence, distant metastasis and reduced cancer-specific survival? Colorectal Dis. 2011; 13:272-283.
26. Kruschewski M, Rieger H, Pohlen U, Hotz HG, Buhr HJ. Risk factors for clinical anastomotic leakage and postoperative mortality in elective surgery for rectal cancer. Int J Colorectal Dis. 2007; 22:919-927.

27. Sorensen LT, Jorgensen T, Kirkeby LT, Skovdal J, Vennits B, Wille-Jorgensen P. Smoking and alcohol abuse are major risk factors for anastomotic leakage in colorectal surgery. Br J Surg. 1999; 86:927-931.

28. Surgical site infection . Clinical Guideline. RCOG Press at the Royal College of Obstetricians and Gynaecologists. 2014; 4-8-2014.

29. Kulu Y, Tarantio I, Warschkow R, et al. Anastomotic Leakage Is Associated with Impaired Overall and Disease-Free Survival after Curative Rectal Cancer Resection: A Propensity Score Analysis. Ann Surg Oncol. 2014:2059-67.

30. Boesen AK, Maeda Y, Rorbaek MM. Perioperative fluid infusion and its influence on anastomotic leakage after rectal cancer surgery: implications for prevention strategies. Colorectal Dis. 2013; 15:e522-527.

31. Eon Y, Le Douy JY, Lamer B, Battini J, Bretagne JF. Quality and completeness of histopathology reports of rectal cancer resections. Results of an audit in Brittany. Gastroenterol Clin Biol. 2006; 30:235-240.

32. Baek JH, Alrubaie A, Guzman EA, Choi SK, Anderson C, Mills S, et al. The association of hospital volume with rectal cancer surgery outcomes. Int J Colorectal Dis. 2013; 28:191-196.

33. Leonard D, Penninckx F, Kartheuser A, Laenen A, Van EE. Effect of hospital volume on quality of care and outcome after rectal cancer surgery. Br J Surg. 2014; 101:1475-1482.

34. Weber WP, Zwahlen M, Reck S, Misteli H, Rosenthal R, Buser AS, et al. The association of preoperative anemia and perioperative allogeneic blood transfusion with the risk of surgical site infection. Transfusion. 2009; 49:1964-1970.

35. Shander A, Spence RK, Adams D, Shore-Lesserson L, Walawander CA. Timing and incidence of postoperative infections associated with blood transfusion: analysis of 1,489 orthopedic and cardiac surgery patients. Surg Infect (Larchmt). 2009; 10:277-283.

36. Komatsu Y, Orita H, Sakurada M, Maekawa H, Hoppo T, Sato K. Intraoperative blood transfusion contributes to decreased long-term survival of patients with esophageal cancer. World J Surg. 2012; 36:844-850.

37. Chen J, Wang DR, Yu HF, Zhao ZK, Wang LH, Li YK. Defunctioning Stoma in Low Anterior Resection for Rectal Cancer: A Meta-Analysis of Five Recent Studies. Hepatogastroenterology. 2011; 59:1828-1831.

38. Matthiessen P, Hallbook O, Rutegard J, Simert G, Sjodahl R. Defunctioning stoma reduces symptomatic anastomotic leakage after low anterior resection of the rectum for cancer: a randomized multicenter trial. Ann Surg. 2007; 246:207-214. 
39. Gastinger I, Marusch F, Steinert R, Wolff S, Koeckerling F, Lippert $\mathrm{H}$. Protective defunctioning stoma in low anterior resection for rectal carcinoma. Br J Surg. 2005; 92:1137-1142.

40. Thoker M, Wani I, Parray FQ, Khan N, Mir SA, Thoker P. Role of diversion ileostomy in low rectal cancer: A randomized controlled trial. Int J Surg. 2014; 12:945-951.

41. Mirnezami A, Mirnezami R, Chandrakumaran K, Sasapu K, Sagar P, Finan P. Increased local recurrence and reduced survival from colorectal cancer following anastomotic leak: systematic review and meta-analysis. Ann. Surg. 2011; 253:890-9.
42. Mrak K, Eberl T, Laske A, Jagoditsch M, Fritz J, Tschmelitsch J. Impact of postoperative complications on long-term survival after resection for rectal cancer. Dis Colon Rectum. 2013; 56:20-28.

43. Ptok H, Marusch F, Meyer F, Schubert D, Gastinger I, Lippert H. Impact of anastomotic leakage on oncological outcome after rectal cancer resection. Br J Surg. 2007; 94:1548-54.

44. Robert Koch-Institut (Hrsg) und die Gesellschaft der epidemiologischen Krebsregister in Deutschland e.V.(Hrsg). Krebs in Deutschland 2007/2008. Berlin, Robert-KochInstitut. 4-8-2014. 